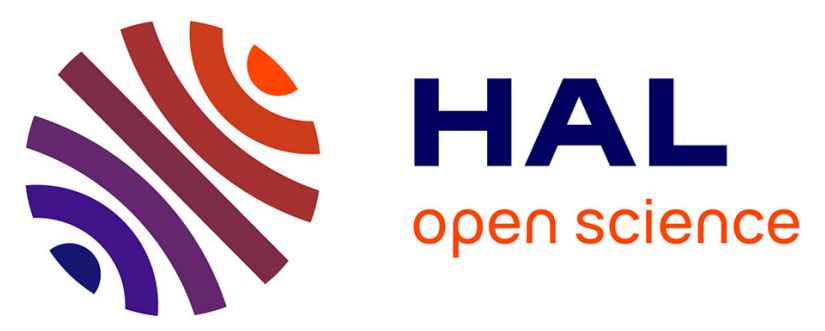

\title{
Polar organic chemical integrative sampler (POCIS): application for monitoring organic micropollutants in wastewater effluent and surface water
}

Cecile Miege, H. Budzinski, R. Jacquet, C. Soulier, T. Pelte, Marina Coquery

\section{- To cite this version:}

Cecile Miege, H. Budzinski, R. Jacquet, C. Soulier, T. Pelte, et al.. Polar organic chemical integrative sampler (POCIS): application for monitoring organic micropollutants in wastewater effluent and surface water. Journal of Environmental Monitoring, 2012, 14 (2), p. 626 - p. 635. 10.1039/C1EM10730E . hal-00856692

\section{HAL Id: hal-00856692 https://hal.science/hal-00856692}

Submitted on 2 Sep 2013

HAL is a multi-disciplinary open access archive for the deposit and dissemination of scientific research documents, whether they are published or not. The documents may come from teaching and research institutions in France or abroad, or from public or private research centers.
L'archive ouverte pluridisciplinaire HAL, est destinée au dépôt et à la diffusion de documents scientifiques de niveau recherche, publiés ou non, émanant des établissements d'enseignement et de recherche français ou étrangers, des laboratoires publics ou privés. 


\title{
J. Environ. Monit., DOI:10.1039/C1EM10730E
}

\section{Polar organic chemical integrative sampler (POCIS): application for monitoring organic micropollutants in wastewater effluent and in surface water}

\author{
Cécile Miège ${ }^{1}$, Hélène Budzinski ${ }^{2}$, Romain Jacquet ${ }^{1}$, Coralie Soulier ${ }^{2}$, Thomas Pelte ${ }^{3}$, Marina Coquery ${ }^{1}$
}

${ }^{1}$ Cemagref, U.R. MALY, 3bis quai Chauveau, 69336 Lyon, France.

${ }^{2}$ Université de Bordeaux 1, ISM-LPTC, 351 cours de la Libération, 33405 Talence, France.

3 Agence de l'eau Rhône Méditerranée \& Corse, 2-4 all Lodz, 69363 Lyon Cedex 07, France.

\section{Address correspondence to: cecile.miege@cemagref.fr}

\section{Introduction}

There have been major changes in the way water management policy addresses pollution, one key trend being the continuing integration of micropollutants into freshwater quality parameter targets. Environmental quality requirements have been specified for priority chemical pollutants, notably with the Water Framework Directive (WFD) 2000/60/EC ${ }^{1,2}$. Water resource managers need to be able to produce statements of micropollutant pressures and contamination in water bodies and to issue a diagnostic on whether or not their water resources are in compliance with the environmental quality standards (EQS) for priority substances and whether they contain other substances liable to have adverse effects on aquatic ecosystems. This is a particularly delicate exercise since the list of micropollutants released by anthropogenic activity may count in the thousands - and possibly more. Micropollutants can exert toxic effects even at very low concentrations, down to the $\mu \mathrm{g} . \mathrm{l}^{-1}$ or in some cases the ng. $1^{-}$ 1 , and EQS may set limit values at under the $\mu \mathrm{g} .1^{-1}$, forcing operators to look for extremely powerful analytical techniques for wastewater effluent and surface water quality monitoring. Finally, outside the substances given priority-status, the WFD objectives also extend to any detected pollutant liable to significantly damage the aquatic ecosystem, thus forcing the authorities to run monitoring on "emergent" pollutants whose occurrence and potential ecotoxic effects have not yet been fully assessed.

A first step towards assessing environmental risks is the development of sampling and analytical tools enabling the deployment of monitoring strategies to measure the impact of effluent discharge, such as wastewater treatment plant (WWTP), on aquatic ecosystems. Over the last fifteen years, a broad range of integrative samplers (or "passive" samplers) have been developed, all of which were designed to be more representative of real exposure (time-averaged exposure (TWA) concentrations) and significantly decrease detection limits. Since these samplers are integrative, they can also pinpoint pollution peaks (episodic pollution events). They also preserve chemical information as they prevent contaminant metabolization and depuration that can occur when utilizing biota. Furthermore, integrative sampling theoretically offers better reproducibility than sampling with biota as it is independent of biological stressors. The options for deploying standard configurations make it possible to generate readily-comparable results. Finally, integrative samplers open up possibilities for combined chemical-biological analysis of micropollutants in natural or anthropogenically-impacted water.

POCIS (polar organic chemical integrative sampler) sampling is well-suited to monitoring hydrophilic compounds such as medical drugs ${ }^{5-8}$, surfactants (nonylphenols) ${ }^{3,7-10}$, triazines ${ }^{3,4,11}$ and caffeine ${ }^{5,12}$. POCIS is currently used to (qualitatively) screen for organic hydrophilic contaminants in aquatic environments ${ }^{13-15}$. It is well adapted to sampling micropollutants in surface water ${ }^{12}$ but much less often employed in effluents ${ }^{5,16-18}$. POCIS samplers present characteristics that open up possibilities for detecting compounds present at concentrations below the limits of detection in grab samples, such as the steroidal hormones that have been identified as toxic even at ultra-low concentrations $\left(<\right.$ ng..$\left.^{-1} ;{ }^{13}\right)$. The power of integrative sampling was demonstrated in a New Jersey river, where a POCIS sampler detected 32 contaminants while grab sampling only detected from 9 to $24^{3}$. Furthermore, POCIS can be coupled with ecotoxicology tests to assess the potential toxicity of mixtures of organic micropollutants present intermittently and at concentrations that can be below the detection limits of the biological methods currently available ${ }^{19-22}$.

The aim of this paper is to review the in situ application of POCIS employed for organic micropollutant monitoring in wastewater effluent and in surface water. We start with a brief introduction to the tool and how it works, covering theoretical and practical aspects of in situ deployment, before moving on to address its potential benefits 
and limitations, based largely on results obtained through the AMPERES research project ("Analysis of priority and emerging micropollutants in wastewaters and surface waters"). Within the framework of the AMPERES project, POCIS samplers were deployed in 5 sampling campaigns led between November 2007 and September 2008 on different French rivers: the Saône, the Jalle d'Eysines, the Ardières, the Bourbre and the Seine. The POCIS were installed in these rivers upstream and downstream of WWTPs outflow, as well as in the treated effluent discharge. Several families of organic compounds were studied, covering a broad panel of hydrophobicity: some industrial substances such as alkylphenols and bisphenol A; 5 oestrogen hormones; a number of pharmaceuticals from several therapeutic classes, including 9 antidepressants, 6 anti-inflammatory drugs, 10 beta-blockers, 3 bronchodilators and a hypolipidemic; plus theophylline and caffeine (Table 1). The POCIS were environmentallyexposed up to 28 days in order to study the in situ kinetics and linear response of micropollutant accumulation. Sampling repeatability was verified by exposing the POCIS in triplicate. In order to assess the applicability of the POCIS tool, grab samples were taken from each site at regular intervals throughout the time the POCIS were exposed in situ. For oestrogen hormone and beta-blocker analysis, accumulation kinetics and sampling rate were studied in situ. The studies on alkylphenols, bisphenol A and the other drugs were led in the laboratory. We also undertook studies to identify a compound candidate for use as an internal standard or a performance reference compound (PRC).

\section{Background on POCIS samplers}

\section{Introduction to POCIS samplers}

The POCIS consists of a flat disk-shaped microporous hydrophilic membrane (most often $100 \mathrm{~nm}$ pore-size polyethersulfone) enclosing an adsorbent solid phase. There are currently two phase configurations: one is a pesticide-specific configuration (a mixture of $80 \%$ modified polystyrene-divinylbenzene resin and $20 \%$ carbonaceous sorbent, i.e. Ambersorb 1500, deposited on a steric exclusion copolymer, i.e. styrene divinylbenzene, $\mathrm{S}-\mathrm{X} 3$ ), while the other is more pharmaceutical-specific (Oasis HLB ${ }^{\circledR}$, polymeric-phase divinylbenzene with a polar monomer, i.e. N-vinylpyrolidone) ${ }^{3,15}$. The POCIS deployed under the AMPERES project employed the second phase configuration. The membrane acts as a filter (sampled fraction: dissolved fraction $<100 \mathrm{~nm}$ ) while the enclosed phase acts as an accumulator. The assembly is submerged in the aquatic environment. The organic compounds sampled are largely hydrophilic (log octanol-water partitioning coefficients, or log Kow, should be below 4 to allow a significant concentration factor).

A conventional POCIS device (Fig. 1) has a $5.4 \mathrm{~cm}$ exposed membrane diameter, corresponding to an effective exposed surface area of $45.8 \mathrm{~cm}^{2}$, and contains $200 \mathrm{mg}$ of adsorbent phase.

Fig. 1: Schematic illustration of a POCIS device.

\section{Operating principle}

Integrative samplers exposed in situ demonstrate 3 accumulation phases (Fig. 2):

- Phase 1, which is time-integrative, during which compound accumulation kinetics follow a pseudo-linear curve (when the concentration in the water phase is kept constant);

- The intermediate phase 2, during which accumulation kinetics are curvilinear;

- The stationary phase 3 , which corresponds to the equilibrium compound distribution between integrative sampler and aqueous phase being sampled.

The timespan of each of these phases is dependent on the compounds sampled and exposure conditions. For instance, when sampling the beta-blockers acebutolol, atenolol, bisoprolol, metoprolol, propranolol and sotalol, the linear phase lasts at least 15 days ${ }^{17}$.

Fig. 2: The three POCIS accumulation phases: integrative (Phase I), curvilinear (Phase II) and equilibrium (Phase III) - are governed by exposure time ${ }^{23}$. 
The process of accumulation in the POCIS is essentially adsorption on the internal solid phase after contaminants passively diffuse through the hydrophilic membrane. In order to assess the time-averaged ambient concentration of POCIS-available contaminants, the POCIS is exposed during the linear-phase (phase I) regime, after which a calculation is made based on equation 1 below:

$\mathrm{C}_{\text {water }}=\mathrm{C}_{\text {pocis }} \cdot \mathrm{M}_{\text {pocis }} / \mathrm{Rs} \cdot \mathrm{t}$

where: $\quad C_{w a t e r}$ is the mean contaminant concentration (over the sampling period) in the ambient water $\left(\mu \mathrm{g} .1^{-1}\right)$; $\mathrm{C}_{\mathrm{pocis}}$ is the concentration in the POCIS ( $\left.\mu \mathrm{g} \cdot \mathrm{g}^{-1}\right) ; \mathrm{M}_{\text {pocis }}$ is the mass of adsorbent phase in the POCIS (g); Rs is the sampling rate $\left(1 . \mathrm{d}^{-1}\right)$, which corresponds to the volume of water purified per unit-of-time; and $t$ is the total exposure time $(\mathrm{d})$.

The sampling rate (Rs) is specific to each compound, and is therefore critical for calculating the ambient concentration. It is determined in the laboratory, at the same time as the linear dynamic range, under controlled temperature and turbulence conditions $\left(\mathrm{Rs}_{\mathrm{lab}}\right)$. However, these conditions may prove different in situ (e.g., because of water flow differences), and also if a biofilm forms on the POCIS membrane. This is why in most cases, $\mathrm{Rs}_{\text {lab }}$ values cannot be directly exploited to calculate an in situ ambient concentration but must be adjusted first.

These $\mathrm{Rs}_{\mathrm{lab}}$ values can be adjusted using one or more PRC that are placed inside the integrative sampler before it is exposed in situ. PRCs are non-interfering compounds not found in the ambient waters to be sampled (such as deuterated compounds), and PRC desorption during the exposure period can be used to correct the in situ Rs. According to Petty et al. ${ }^{13}$, once the desorption kinetics of a PRC have been determined in-lab $\left(\mathrm{ke}_{\mathrm{lab}}\right.$, in $\left.\mathrm{d}^{-1}\right)$ and in situ $\left(\mathrm{ke}_{\mathrm{in} \mathrm{situ}}\right.$, in $\left.\mathrm{d}^{-1}\right)$, it is then possible to adjust the lab-estimated sampling rate $\left(\mathrm{Rs}_{\mathrm{lab}}\right)$ for each compound. These corrected sampling rates $\left(\mathrm{Rs}_{\text {in situ }}\right)$ are obtained from the following equation:

$\mathrm{Rs}_{\text {in situ }}=\left(\mathrm{ke}_{\text {in situ }} / \mathrm{ke}_{\text {labo }}\right) \cdot \mathrm{Rs}_{\text {labo }}$

In strict logic, it is these $\mathrm{Rs}_{\text {in situ }}$ values that need to be used to calculate ambient concentration as in equation 1 . Unfortunately, though, the main difficulty is to find a compound that can significantly desorb during periods of exposure, which is a tricky task when using a solid receiving phase which functioning is based on adsorption processes - as is the case with POCIS devices (in contrast with the liquid receptor phases that introduce partition processes, as is the case with SPMD ${ }^{\mathrm{a}}$ samplers ${ }^{24}$ ). Recent research has shown that deuterated deisopropylatrazine (DIA d5) could act as PRC for herbicide sampling in surface water ${ }^{11}$. Where possible, analysts should use a combination of PRCs characterized by different hydrophobicities (i.e. log Kow). Empirical and theoretical models have been developed and applied for SPMDs ${ }^{25}$, making it possible to adjust the sampling rates of hydrophobic compounds like PAHs and PCBs that have log Kow inside the range of those of the PRCs used.

Finally, it is equally possible to directly assess Rs and accumulation kinetics in situ ${ }^{17,26}$, in a process that entails in situ campaigns deploying POCIS at different exposure durations. These Rs values also need to be verified for each new campaign where environmental conditions (temperature, water velocity, biofouling) are liable to change and consequently modify the Rs measurements. However, direct in situ measurement of Rs hinges on the presence and quantification of compounds in the medium studied, and on their concentrations remaining relatively constant throughout the exposure period.

\section{Field deployment of the POCIS devices}

The draft standard ISO/DIS 5667-23 details the precautionary measures to be followed for in situ environmental exposure of integrative samplers.

Before being deployed in situ, the POCIS must, if possible, be spiked with one or more PRCs. The POCIS devices must be kept out of sunlight, generally inside hermetically-sealed stainless steel boxes at $4^{\circ} \mathrm{C}$ or at $-20^{\circ} \mathrm{C}$ when they are spiked with PRC. For the commercially-sourced POCIS, the adsorbent phase will need to be weighed to check the exact quantity contained in the device.

During exposure, POCIS replicates (generally $\mathrm{n} \geq 2$ ) are placed in protective cages that let water run through (typically stainless steel), and these cages are submerged underwater without touching the sediment bed. Analysts

\footnotetext{
${ }^{\text {a }}$ Semi-Permeable Membrane Device
} 
are strongly advised to run a field blank for each tested site (POCIS exposed to the same transport conditions but not exposed to the water).

Water current and temperature have to be measured at regular intervals. Furthermore, the main physico-chemical parameters of the target water should be measured (i.e., dissolved organic carbon, conductivity, $\mathrm{pH}$, particulate suspended matter) as they can trace water quality changes over time and also might influence the POCIS-available fraction. Biofouling needs to be closely monitored and, if excessive, may prompt a cutback in even exposure time, but it does not require treatment. During the AMPERES project campaigns, we registered light and largely superficial biofouling after 21-day environmental exposure. Optimal exposure time (under linear conditions) for the full set of AMPERES project compounds was 15 days.

At completion of the exposure period, the POCIS devices are placed in hermetically-sealed stainless steel boxes or wrapped in aluminum foil and placed in a freezer plastic bag, and transported refrigerated back to the laboratory. They are then cleaned with ultrapure water, and the adsorbent phase is eluted with organic solvents under predefined conditions. The organic eluate may then be purified for chromatographic analysis according to the compounds to be determined.

\section{Sampling rates (Rs) for the studied compounds}

\section{In-lab and in situ Rs assessment methods}

The abbreviations used for the studied compounds are detailed in Table 1. The POCIS that were used in the AMPERES project were home-made, i.e. membranes and adsorbant phases were bought separately and assembled in the laboratory after precise weighting of the quantity of adsorbant phase.

In-lab: Rs assessment was done in a tapwater-filled $70-\mathrm{L}$ aquarium under dark conditions, at $20.5^{\circ} \pm 2^{\circ} \mathrm{C}$. Pharmaceutical-configuration POCIS devices (Exposmeter, $45.8 \mathrm{~cm}^{2}$ effective sampling surface area) were fitted on a rotary carousel containing 24 POCIS devices. This carousel system could be used to test two different water velocities according to rotating distance $(2 \mathrm{~cm}$ or $10 \mathrm{~cm})$ from the spindle $\left(0.21\right.$ and $\left.0.46 \mathrm{~m} . \mathrm{s}^{-1}\right)$.

Water samples were collected daily, and a triplicate POCIS was removed on day 3, 7, 10 and 14. For alkylphenols, their physico-chemical properties (i.e. lipophilic and amphiphilic nature) prompted us to analyze the polyethersulfone POCIS membranes as well as the adsorbent phase. These membranes do not accumulate pharmaceutical compounds, as shown by Togola \& Budzinski ${ }^{5}$. The sampling rates obtained at both water velocities were within less $20 \%$ of variation, except for terbutaline, salbutamol, paracetamol, theophylline, aspirin, diclofenac, 4-NP1EO and 4-NP2EO. Comparative data (at 0.21 and $0.46 \mathrm{~m} . \mathrm{s}^{-1}$ ) are given in supplementary material (Table S1). Table 1 only reports the results for the highest velocity $\left(0.46 \mathrm{~m} \cdot \mathrm{s}^{-1}\right)$.

For the highly hydrophilic compounds with a $\log \mathrm{K}_{\mathrm{OW}} \leq 1$ (terbutaline, salbutamol, paracetamol, caffeine, theophylline and aspirin), the accumulation curve in the adsorbent phase was only slightly sloped and non-linear. Significant amounts of the more hydrophobic compounds with a $\log \mathrm{K}_{\mathrm{OW}}>5$ (4-NP, 4-t-OP, 4-NP1EC, 4-NP1EO, 4-NP2EO and BPA) resided in the membrane. At 14 days, 4-NP, 4-t-OP, 4-NP1EO, 4-NP2EO and 4-NP1EC were quantified in the adsorbent phase at $27 \%, 70 \%, 15 \%, 10 \%$ and $90 \%$, respectively, the remainder being captured in the membrane. The quantities of these compounds found in the membranes decreased according to exposure time, which suggests they were first absorbed by the membrane before penetrating the adsorbent phase. In this study, we chose to recover the adsorbent phase for subsequent analysis using Milli-Q water (Millipore) so as not to disturb the membrane-receiving phase equilibrium. This decision was prompted by studies by Arditsoglou et al. ${ }^{7}$ and Li et $a l .{ }^{12}$ stating that using methanol could eluate the hydrophobic compounds found in the membrane and thus bias the Rs end-values calculated.

In situ: Rs assessment was performed within the framework of three measurement campaigns, one on the Saône river (at Fontaine-sur-Saône) in November 2007, one on the Ardières river (at Beaujeu-sur-Ardières) in June 2008, and one on the Bourbre river (at Bourgoin-Jallieu) in September 2008. The POCIS were installed upstream and downstream of WWTPs as well as in the treated effluent released. These pharmaceutical-configuration POCIS were exposed for 7, 14 and 21 days, with triplicates taken at 7 or 14 days depending on study site. In parallel to the POCIS samples, grab samples were also carried out at 0, 7, 14 and 21 days, and local exposure environment conditions were recorded (contaminant concentrations, temperature, water channel velocity, dissolved organic carbon, conductivity). To facilitate comparison against POCIS samples, analyses on the grab sample contaminants 
were performed on the dissolved fraction (filtered through $0.7 \mu \mathrm{m}$ filter pore size). The Rs values obtained over the 3 campaigns (for 9 sites) were pooled and averaged (Table 1).

The AMPERES study design also led us to search for candidate PRCs. All 3 beta-blockers (ATE D7, MET D7 and PROP D7) and the 4 commercially-available deuterated hormones (E1-d4, $\beta$-E2-d2, EE2-d4, E3-d2) were assayed. They were added to the POCIS before exposure, and their depuration (or loss) during in situ exposure was measured. Only ATE D7 appeared to be a good potential candidate PRC, registering day-15 exposure losses of $60 \%$ for the Bourbre river campaign and 50\% for the Ardières river campaign. These results need to be confirmed under laboratory conditions. No PRC-based adjustment factors were used on the results reported here.

Analytical methods: information on the analytical aspects (pre-treatment and chromatographic analysis) for POCIS and water samples are detailed in previous papers ${ }^{27,28}$.

\section{Comparison of Rs values for the studied compounds}

Table 1 reports Rs values from the literature together with the Rs values obtained (in-lab or in situ) under the AMPERES project.

Table 1: Sampling rates (Rs in $1 . \mathrm{d}^{-1}$ ) for the target compounds studied using POCIS with a $45.8 \mathrm{~cm}^{2}$ effective exposed surface area; results from the AMPERES project (underlined) or from literature reports (non-underlined). Laboratory measurement conditions: turbulent media at between 15 and $25^{\circ} \mathrm{C}$, unless stated otherwise.

In Table 1, the differences in Rs values obtained for the same compound are due to differences in POCIS temperature, turbulence or exposed surface area conditions. Under standard conditions (turbulent media, temperature in the range $15^{\circ} \mathrm{C}$ to $25^{\circ} \mathrm{C}$, and using POCIS with a $45.8 \mathrm{~cm}^{2}$ effective exposed surface area), POCIS sampling rates are generally less than $11 . \mathrm{d}^{-1}$. Note that in comparison, the Rs of polycyclic aromatic hydrocarbons (PAH) sampled by SPMDs (with a $460 \mathrm{~cm}^{2}$ effective exposed surface area) are around the $51 . \mathrm{d}^{-1}$. This means that the concentration effect between water and sampler (i.e. the decrease of limit of detection) is clearly stronger for hydrophobic-dedicated SPMDs than for hydrophilic-dedicated POCIS. Knowing that Rs are directly proportional to exposed surface area, we note that the concentration effect per $\mathrm{cm}^{2}$ of effective surface area is higher for POCIS.

Direct in situ studies on Rs are few and far between ${ }^{17,26}$. Under the AMPERES project, Rs were determined in situ for 6 beta-blockers (ACE, ATE, BIS, MET, PROP, SOT). Rs could not be determined for (i) 4 beta-blockers (BET, $\mathrm{NAD}, \mathrm{OXP}, \mathrm{TIM})$ and 2 oestrogenic hormones (EE2 and $\alpha \mathrm{E} 2$ ) that were not detected or measured at very low concentrations and (ii) 3 hormones (E1, $\beta \mathrm{E} 2$ and E3) that gave concentrations close to the limits of quantification and non-linear kinetics curves (as the concentrations were very low, probably non-constant). For a given zone (e.g. Bourbre river), Rs values tended to be lower in WWTP effluents, which are characterized by higher conductivity and higher concentrations of particulate suspended matter and dissolved organic carbon. However, attempts to assess an effluent Rs are complicated by an inter-zone variability - caused by factors such as different temperature conditions (campaigns performed in different seasons) - that mask intra-zone trends. These data will be reported in depth in a separate paper. The ultimate purpose of these in situ measurements is to determine whether the variance in Rs integrating different temperatures (seasons), channel flows or media types remains acceptable, or whether specific Rs should be determined according to the most influential environmental conditions.

At equivalent conditions, Rs values found under the AMPERES project were generally very similar to those previously reported, with the exception of certain alkylphenols. The Rs obtained for 4-NP, 4-NP1EO et 4-NP2EO under the AMPERES project were 10 to 100 -fold lower than the Rs values reported in the literature. This difference may stem from the fact that previous studies ${ }^{7,12}$ used methanol to recover the POCIS phase before extraction when the device is dismantled, potentially introducing hydrophobic compounds present in the membrane. Clearly, further developments are needed in order to decide on the procedures best-adapted to these compounds, not just for Rs calculations but also for how to handle the POCIS after in situ exposure (type of phase rinse-down).

Rs have been determined for several other pharmaceutical substances not reported in Table 1, as well as for biocides ${ }^{12,15,26,29,31}$. Other studies have been carried out to determine the Rs of pesticides such as triazines and 
phenylurea and some of their metabolites, sulphonylurea derivatives, triketones and chloroacetanilide ${ }^{4,11,15,29}$. Rs have also been assessed for more hydrophobic compounds such as PAHs (pyrene, benzo[a]pyrene), other alkylphenols (4-tert-butylphenol, 4-n-butylphenol, 4-n-pentylphenol) and organic halogens (DDT, PBDE 47, lindane), in both freshwater ${ }^{8}$ and seawater ${ }^{9}$, and also with biofouling in the membranes ${ }^{10}$.

\section{Examples of POCIS applications}

\section{Application of POCIS to assess exposure time-averaged ambient dissolved concentration}

POCIS (triplicates) were exposed (1) in the Jalle d'Eysines river both upstream and downstream of the WWTP at Cantinolle (near Bordeaux) for 7 and 14 days, and (2) in the WWTP effluent for 7 days at two separate places: midchannel (characterized by heavy flow) and in the pool (characterized by zero turbulence). At the same time, grab samples were also carried out in the Jalle d'Eysines at 0,2, 7, 9, 12 and 14 days and in the WWTP at 0, 2 and 7 days. TWA concentrations after POCIS sampling were calculated using equation 1 and lab-assessed Rs values (Table 1), and compared against the concentrations measured after grab sampling and on the dissolved fraction $<0.7 \mu \mathrm{m}$ (Fig. 3).

Standard deviations on triplicate concentrations were lower on POCIS samples than grab samples, except for the ethoxylated alkylphenols (4-NP1EO and 4-NP2EO). Overall, there was good agreement between calculated concentrations and measured concentrations in the Jalle d'Eysines river (Fig. 3a and b), particularly at 14 days. This highlights that channel flow and temperature conditions were equivalent between the in-lab Rs assessment and the in-river sampling. If we had used the literature values for Rs, then the dissolved concentrations, especially of 4NP, would have been 10 to 100 -fold higher.

In the WWTP effluents, agreement between calculated concentrations and measured concentrations was good in the pool (Fig. 3c). Fig. 3d illustrates the influence of channel flow on in-POCIS accumulation of alkylphenols and pharmaceuticals, as higher quantities accumulate at higher in-channel flows. From these two figures it is inferred that the calculated and measured concentrations in mid-channel were not in agreement when the Rs determined in laboratory were used. This means that the temperature and channel flow conditions employed for the in-lab Rs assessments were closer to pool conditions.

In some cases, using POCIS devices makes it possible to lower the limits of detection (see Fig. 3a and b, after 7d exposure): for instance, gemfibrozil was detected up and downstream of the WWTP by POCIS sampling but not by grab sampling.

POCIS is even capable of overcoming certain matrix effects, as shown in Fig. $3 \mathrm{c}$ where naproxene, diclofenac and ketoprofene were detected in POCIS samples but not in grab samples. In this case, POCIS sampling, unlike grab sampling, selectively ignores the interfering compounds. In this example, the interfering compounds caused major signal reduction when extractions were analyzed by liquid chromatography coupled with tandem mass spectrometry (LC-MS/MS). In other cases, POCIS sampling, unlike grab sampling, can actually amplify the interfering compounds and thus strongly enhance the matrix effects, as was the case with the internal standards used for hormones (E2 acetate) and beta-blockers (MET Impurity A), measured by LC-MS/MS. For these molecules, the matrix effect leads to overestimated hormone and beta-blocker concentrations. It should consequently be prevented during analysis, by diluting the POCIS extracts before injection into the chromatography system ${ }^{17}$.

Fig. 4 compares beta-blocker concentrations in the Seine River (near the city of Aubergenville) measured after grab sampling against the concentrations calculated after POCIS sampling using the Rs values obtained in situ (Table 1). The concentrations were equivalent for ACE, MET, PROP, BIS, but differed two-fold for the most hydrophilic beta-blockers ATE and SOT, which remains acceptable. In this example, POCIS sampling, unlike grab sampling, was unable to detect NAD, OXP and BET. The decrease in analytical limits of detection is therefore not a generalized feature but is dependent on other factors - notably the compound targeted.

POCIS sampling demonstrated very satisfactory repeatability. For example, the coefficient of variation on betablocker concentrations assessed after POCIS sampling in the Seine River at Aubergenville (Fig. 4) was less than $14 \%$. 
Fig. 3: Comparative analysis of dissolved-phase concentrations of pharmaceuticals and alkylphenols measured after grab sampling ( $n=3$ at 7 days, $n=6$ at 14 days) and the concentrations calculated by POCIS sampling ( $n=3$, 7day and 14-day exposure) using the Rs values obtained in-lab, in the Jalle d'Eysines river, a) upstream and b) downstream, c) in the WWTP effluent at nearby Cantinolle; and d) comparative analysis (pool vs. mid-channel) of the quantities accumulated in the POCIS devices placed in the effluent.

Fig. 4: Comparison of dissolved-phase concentrations on beta-blockers in the Seine River measured after grab sampling ( $\square, n=3$, samples taken at $\mathrm{d} 0, \mathrm{~d} 7$ and d14) against the concentrations calculated after POCIS sampling (, $\mathrm{n}=3$, 14-day exposure) using the Rs values obtained in situ. (nd: not detected).

\section{Application of POCIS for screening}

POCIS samplers can also be deployed in more qualitative applications (i.e. screening) without having to calculate exposure TWA ambient concentrations. Straightforward analysis of the quantity of contaminants accumulated in POCIS devices can highlight concentration gradients between sites presenting different contamination profiles. In the example illustrated in Fig. 5, POCIS allowed to observe the impact of a WWTP outflow on the quality of the natural receiving waters, with increasing beta-blocker concentrations between the river upstream of the WWTP, the river downstream of the WWTP, and the WWTP effluent. In this example, POCIS sampling, unlike grab sampling, was unable to detect $\mathrm{E} 3$ or $\beta \mathrm{E} 2$.

In addition to the information given under section "Application of POCIS to assess exposure time-averaged ambient dissolved concentration", the POCIS-enabled decrease of limits of detection compared to direct water sampling is not a generalized feature but is dependent on compound and probably also on the type of pollution released to a river (chronic or accidental).

Fig. 5: Cross-comparison of beta-blocker and hormone quantities accumulated a) by POCIS ( $\mathrm{n}=1$, 21-day exposure) and b) per litre of water ( $\mathrm{n}=4$, grab sample at $0,7,14$ and 21 days) in the dissolved phase of the Bourgoin-Jallieu WWTP effluent and the nearby Bourbre river, upstream and downstream of the WWTP outflow (OXP, BET, EE2 and bE2 remained undetected in either POCIS or grab samples).

\section{POCIS technology transfer to water basin managers}

Aquatic ecosystem managers are increasingly receptive to the performances being registered by integrative samplers and their potential applications for chemical quality monitoring on aquatic ecosystems. The key advantages of integrative samplers are their ability to integrate a contamination period, to concentrate the pollutants present and thus detect contaminants that can only be found at trace concentrations in aquatic ecosystems, and to detect accidental pollution or episodic peaks in pollution. From a practical perspective, the transfer of POCIS technology to regulatory water basin management for chemical quality monitoring appears a realistic possibility in the near future, especially where the pollution is greatly diluted, such as lakes or reservoirs, major deep-flow rivers, and coastal waters. The same technique can be used for discharge monitoring and tracking, either in the collection systems or sewage outlets or in the receiving water body immediately downstream WWTP outflow for instance. This sampling tool will need to offer added-value compared to conventional sampling and analysis protocols (i.e. grab sampling water, or automated $24 \mathrm{~h}$-average or weekly-average sampling). Candidate users for this type of device will be focusing on a range of factors: cost price and running costs, operational reproducibility (between samples and between analyses) avoiding supplier induced or inter-operator variability, spatial and temporal representativeness of the results, analytical performance in terms of the panel of substances sampled and reduction of the limit of detection, options for producing diagnostics reports for regulatory requirements (environmental quality standards, chemical or ecological status reports under the Water Framework Directive, compliance on authorized discharge levels, and etc.). Knowledge acquired through the AMPERES programme can shed light on many of these factors.

POCIS devices are now easy to obtain, and they are commercially available at a unit price of just a few dozen euros. They can also be hand-built, enabling to ensure fully homogeneous device weight and composition. This may be a key factor, since recent research has demonstrated a degree of variability in commercially-available 
products that could significantly influence the final concentration data ${ }^{17}$. If this problem is not solved, it could hinder the process of transferring the technique to field operatives who are particularly stringent on the accuracy of the final concentration figures. Handling-wise, POCIS device and the logistics required for field deployment are relatively lightweight. The risk of operator-related variability appears minimal given the simplicity of the field protocol. There is now a draft standard ${ }^{32}$ that could be recommended as a reference guideline. However, clarifications are needed to address a couple of weaknesses tied to in situ POCIS sampling: what kind of recommendation should be issued on positioning the POCIS not too near the water surface nor too close to the sediment bed? and more importantly, what standard exposure period should be recommended to ensure crosscomparability of the results obtained? Looking at this second point, work led under the AMPERES project has clearly shown how optimal exposure period is compound-dependent. This makes it useful to produce a practical hands-on read-off chart designed to help field operators adopt a well-adapted and widely-shared protocol. Lastly, from a longer-term perspective looking to assess exposure time-weighted ambient concentrations: what kind of Rs should operatives be using, and what kind of strategy (and which PRCs) should be employed to correct for environmental conditions?

\section{Conclusions and perspectives}

The AMPERES project has improved knowledge on integrative samplers, particularly POCIS, and has extended their scope of application. Although the POCIS sampling technique was initially developed for surface waters, it has proven well-geared to sampling pharmaceutical micropollutants and alkylphenols in the dissolved phase of WWTP effluents. Its utility in terms of measuring hormones and bisphenol-A concentrations has yet to be demonstrated.

Results from the AMPERES project have illustrated the diagnostic capacity offered by POCIS tools. The key advantages of POCIS highlighted are: their ability to integrate a contamination period spanning several weeks; their ability to work with lower limits of detection and quantification (at least for certain compounds) than conventional grab sampling or automated mean daily sampling; the options for deploying standard configurations to generate readily-comparable results; their cost-effectiveness compared to deploying multiple grab samplers or automated sample collectors; easy deployability. However, we also identified certain limitations that will need to be addressed to facilitate the transfer of POCIS technology to in situ operative, i.e. their ability to enable assessment of a mean ambient water concentration (and the possibility of using PRCs), and a lack of homogeneity among commerciallyavailable samplers (often involving roughly-dosed adsorbent phase contents).

\section{Acknowledgements}

This study was supported by the French National Research Agency and the Water Agency Rhône Méditerranée \& Corse, in the framework of the AMPERES project. The authors thank all technical staff of analytical laboratories and process teams for their contribution to the production of the data.

\section{References}

1. European Community (2000). Directive 2000/60/CE of the European Parliament and of the Council of 23 October 2000 establishing a framework for Community action in the field of water policy. Off. J Eur. Union L 327: 1-73.

2. European Community (2008). Directive 2008/105/EC of the European Parliament and of the Council of 16 December 2008 on environmental quality standards in the field of water policy, amending and subsequently repealing Council Directives 82/176/EEC, 83/513/ EEC, 84/156/EEC, 84/491/EEC, 86. Off. J Eur. Union, L348: 84-97.

3. Alvarez D., Stackelberg P.E., Petty J.D., Huckins J.N., Furlong E.T., Zaugg S.D., Meyer M.T., Chemosphere, 2005, 61, 610-622.

4. Martinez-Bueno M.J., Hernando M.D., Agüera A., Fernandez-Alba A.R., Talanta, 2009, 77, 1518-1527.

5. Togola A., Budzinski H., Anal. Chem., 2007, 79, 6734-6741.

6. Bartelt-Hunt S.L., Snow D.D., Damon T., Shockley J., Hoagland K., Environ. Pollution, 2009, 157, $786-791$.

7. Arditsoglou A., Voutsa D., Environ. Pollution, 2008, 152, 316-324.

8. Harman C., Boyum O., Tollefsen K.E., Thomas K., Grung M., J Environ. Monit., 2008a, 10, 239-247.

9. Harman C., Tollefsen K.E., Boyum O., Thomas K., Grung M., Chemosphere, 2008b, 72 1510-1516.

10. Harman C., Thomas K.V., Tollefsen K.E., Meier S., Boyum O., Grung M., Marine Pollution Bulletin, 2009, 58, 16711679.

11. Mazzella N., Dubernet J.F., Delmas F., Journal of Chrom.A., 2007, 1154, $42-51$.

12. Li H., Helm P.A., Metcalfe C.D., Environ. Toxicol. Chem., 2010, 29, 1-12. 
13. Petty J.D., Huckins J.N., Alvarez D., Brumbaugh W.G., Cranor W.L., Gale R.W., Rastall A.C., Jones-Lepp T.L., Leiker T.J., Rostad C.E. Furlong E.T., Chemosphere, 2004, 54, 695-705.

14. Alvarez D.A. Development of an integrative sampling device for hydrophilic organic contaminants in aquatic environments, PhD thesis, University of Missouri-Columbia, Columbia, MO, 1999.

15. Alvarez D.A., Petty J.D., Huckins J.N., Jones-Lepp T.L., Getting D.T., Goddard J.P., Manahan S.E., Environ. Toxicol. Chem., 2004, 23, 1640-1648.

16. Jones-Lepp T.L., Alvarez D.A., Petty J.D., Huckins J.N., Arch. Environ. Contam. Toxicol., 2004, 47, 427-439.

17. Jacquet R., C. Miège, C. Soulier, H. Budzinski, M. Coquery. POCIS versus SPMD for in-situ sampling of estrogenic hormones, betablockers and alkylphenols. IPSW (International Passive Sampling Workshop and Symposium), 27-30 May 2009, Prague, Czech Republic.

18. Grabic R., Jurcikova J., Tomsejova S., Ocelka T., Halirova J., Hypr D., Kodes V., Environ. Toxicol. Chem., 2009, 29, 550555.

19. Petty J.D., Poulton B.C., Charbonneau C.S., Huckins J.N., Jones S.B., Cameron J.T., Prest H.F., Environ. Sci. Technol., 1998, 32, 837-842.

20. Vermeirssen E.L.M., Korner O., Schonenberger R., Sutter M.J.F., Burkhardt-Holm P., Environ. Sci. Technol., 2005, 39, 8191-8198.

21. Alvarez D.A., Cranor W.L., Perkins S.D., Clark R.C., Smith S.B., Journal of Environmental Quality., 2008, 37, 10241033.

22. Liscio C., Magi E., Di Carro M., Suter M.J.-F., Vermeirssen E.L.M., Environ. Pollut., 2009, 157, $2716-2721$.

23. Vrana B., Allan I.J., Greenwood R., Mills G.A., Dominiak E., Svensson K., Knutsson J., Morrison G., Trends Anal. Chem., 2005, 24, 845-868.

24. Gourlay C., Gonzalez J.L., Technique Science et Méthode, 2010, sous presse.

25. Huckins, J. N.; Petty, J. D.; Booij, K., Monitors of Organic Chemicals in the Environment: Semipermeable Membrane Devices. Springer Science, chap 3.6 on Water sampling rates, New York, NY (USA), 223 p, 2006.

26. Zhang Z., Hibberd A., Zhou J., Anal. Chem. Acta, 2008, 607, 37-44.

27. Jacquet R., Miège C., Bados P., Schiavone S., Coquery M. Environ. Toxicol. Chem., 2011, in press.

28. Tapie N., Devier M.H., Soulier C., Creusot N., Le Menach K., Aït-Aïssa S., Vrana B. and Budzinski H. Water Science and Technology, 2011, 63 (10), 2418-2426.

29. Hernando M.D., Martinez-Bueno M.J., Fernandez-Alba A.R., Bol. Inst. Esp. Oceanogr., 2005, 21, 37-46.

30. Matthiessen P., Arnold D., Johnson A.C., Pepper T.J., Pottinger T.G., Pulman K.T.G., Science of the Total Environment., 2006, 367, 616-630.

31. MacLeod S.L, McClure E.L., Wong C.S., Environ. Toxicol Chem., 2007, 26, 2517-2529.

32. ISO 5667-23 (2011), Water quality - Sampling - Part 23 : guidance on passive sampling in surface waters, 34 pages 


\section{Figures :}

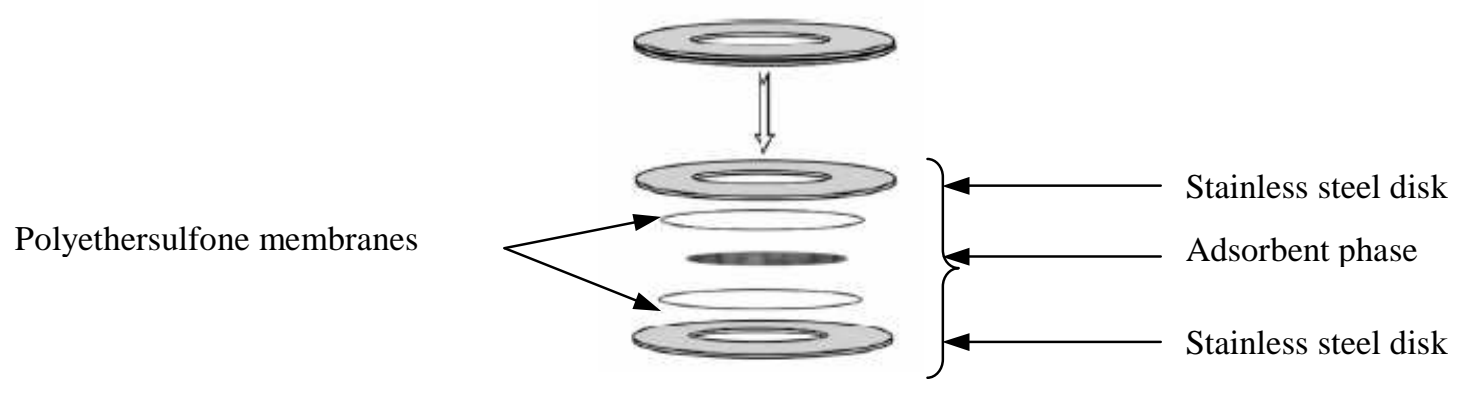

Fig. 1: Schematic illustration of a POCIS device.

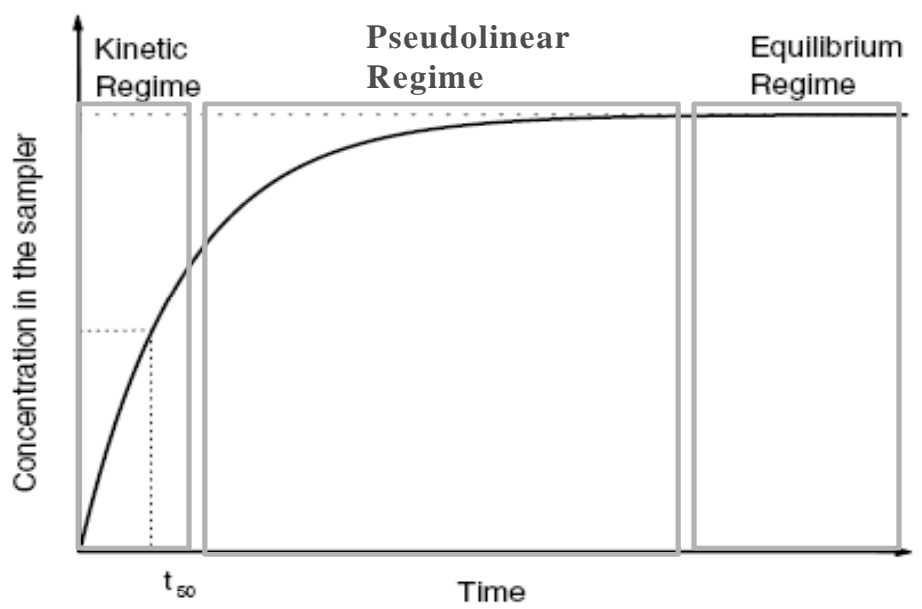

Fig. 2: The three POCIS accumulation phases: integrative (Phase I), curvilinear (Phase II) and equilibrium (Phase III) - are governed by exposure time ${ }^{23}$. 

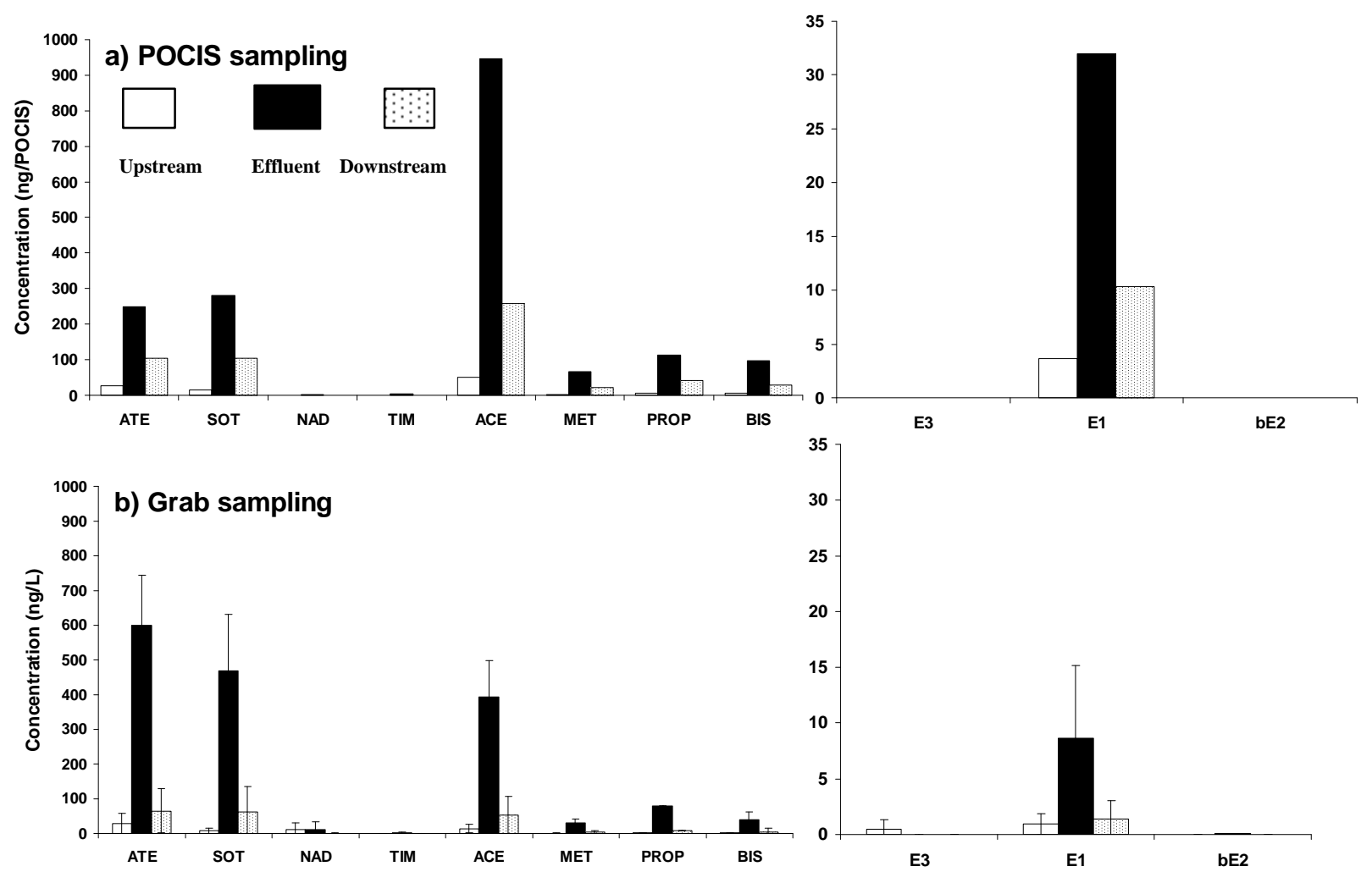

Fig. 5: Cross-comparison of beta-blocker and hormone quantities accumulated a) by POCIS ( $\mathrm{n}=1,21$-day exposure) and b) per litre of water ( $\mathrm{n}=4$, grab sample at $0,7,14$ and 21 days) in the dissolved phase of the Bourgoin-Jallieu WWTP effluent and the nearby Bourbre river, upstream and downstream of the WWTP outflow (OXP, BET, EE2 and bE2 remained undetected in either POCIS or grab samples). 


\section{Tables}

Table 1: Sampling rates (Rs in $1 . \mathrm{d}^{-1}$ ) for the target compounds studied using POCIS with a $45.8 \mathrm{~cm}^{2}$ effective exposed surface area; results from the AMPERES project (underlined) or from literature reports (non-underlined). Laboratory measurement conditions: turbulent media at between 15 and $25^{\circ} \mathrm{C}$, unless stated otherwise.

\begin{tabular}{|c|c|c|c|c|}
\hline Compound (abbreviation) & $\begin{array}{l}\text { Familly of } \\
\text { molecules }\end{array}$ & In-lab $R s$ & In situ Rs & Reference \\
\hline 4-tert-Octylphenol (4-t-OP) & Alkylphenols & $\frac{0.104( \pm 0.030)}{0.120( \pm 0.011)}$ & & 7 \\
\hline 4-Nonylphenol (4-NP) & & $\begin{array}{l}\frac{0.019( \pm 0.014)}{0.1167( \pm 0.0124)} \\
1.199( \pm 0.032)^{\mathrm{b}} \\
1.654( \pm 0.181) \\
2.459( \pm 0.131) \\
0.923( \pm 0.155)^{\mathrm{d}}\end{array}$ & & $\begin{array}{l}7 \\
12 \\
12 \\
12 \\
12\end{array}$ \\
\hline $\begin{array}{l}\text { 4-Nonylphenol } \\
\text { monoethoxylate (4-NP1EO) } \\
\text { 4-Nonylphenol-diethoxylate } \\
\text { (4-NP2EO) } \\
\text { 4-Nonylphenoxyacetic acid } \\
\text { (4-NP1EC) }\end{array}$ & & $\begin{array}{l}\underline{0.010( \pm 0.007)} \\
0.0899( \pm 0.0071) \\
\underline{0.007( \pm 0.007)} \\
0.1173( \pm 0.0179) \\
\underline{0.309( \pm 0.080)}\end{array}$ & & 7 \\
\hline Bisphenol A (BPA) & Phenolated polymer & $\begin{array}{l}\underline{0.014( \pm 0.006)} \\
0.1171( \pm 0.0192) \\
0.040( \pm 0.008)^{\mathrm{a}} \\
0.531( \pm 0.063)^{\mathrm{b}} \\
0.740( \pm 0.036) \\
0.835( \pm 0.058) \\
0.482( \pm 0.066)^{\mathrm{d}}\end{array}$ & $0.55-0.65^{\text {a.e }}$ & $\begin{array}{l}7 \\
26 \\
12 \\
12 \\
12 \\
12\end{array}$ \\
\hline Oestrone (E1) & $\begin{array}{l}\text { Oestrogenic } \\
\text { hormones }\end{array}$ & $\begin{array}{l}0.1199( \pm 0.0177) \\
0.015\end{array}$ & & $\begin{array}{l}7 \\
27\end{array}$ \\
\hline & & $0.040( \pm 0.012)^{\mathrm{a}}$ & $0.3-0.8^{\text {a.e }}$ & 26 \\
\hline $17 \alpha$-Oestradiol $(\alpha-\mathrm{E} 2)$ & & $0.1216( \pm 0.0031)$ & & 7 \\
\hline $17 \beta$-Oestradiol ( $\beta$-E2) & & $\begin{array}{l}0.1145( \pm 0.0139) \\
0.09^{\mathrm{b}} \\
0.129\end{array}$ & & $\begin{array}{l}7 \\
28 \\
28 \\
26\end{array}$ \\
\hline Oestriol (E3) & & $\begin{array}{l}0.037( \pm 0.007)^{\mathrm{a}} \\
0.1571( \pm 0.0041)\end{array}$ & $0.55-0.6^{\text {a.e }}$ & 7 \\
\hline $17 \alpha$-Ethynylestradiol (EE2) & & $\begin{array}{l}0.302( \pm 0.034)^{\mathrm{c}} \\
0.2217( \pm 0.0525) \\
0.018 \\
0.051( \pm 0.007)^{\mathrm{a}}\end{array}$ & & $\begin{array}{l}14 \\
7 \\
27 \\
26\end{array}$ \\
\hline Carbamazepine (Carba) & Antidepressants & $\begin{array}{l}\underline{0.332( \pm 0.043)} \\
0.112( \pm 0.023)^{d} \\
0.348( \pm 0.116) \\
0.230( \pm 0.016)^{b} \\
0.397( \pm 0.018) \\
0.561( \pm 0.024) \\
0.235( \pm 0.046)^{d} \\
0.72 \\
0.68\end{array}$ & $0.2-0.1^{\text {a.e }}$ & $\begin{array}{l}26 \\
29 \\
29 \\
12 \\
12 \\
12 \\
12 \\
5 \\
5\end{array}$ \\
\hline Diazepam (Diaz) & & $\begin{array}{l}\underline{0.402( \pm 0.076)} \\
0.19 \\
0.32\end{array}$ & & $\begin{array}{l}5 \\
5\end{array}$ \\
\hline Nordiazepam (Nordiaz) & & $\begin{array}{l}\underline{0.387( \pm 0.084)} \\
0.16 \\
0.22\end{array}$ & & $\begin{array}{l}5 \\
5\end{array}$ \\
\hline Amitriptyline (Ami) & & $\begin{array}{l}\frac{0.411( \pm 0.118)}{0.22} \\
0.53\end{array}$ & & $\begin{array}{l}5 \\
5\end{array}$ \\
\hline
\end{tabular}


Doxepin (Dox)

Imipramine (Imi)

Alprazolam (Alpra)

Bromazepam (Broma)

Fluoxetine (Fluox)

Ibuprofen (Ibu)

Paracetamol (Para)

Ketoprofen (Keto)

Naproxen (Napro)

Aspirin (Asp)

Diclofenac (Diclo)

Acebutolol (ACE)

Atenolol (ATE)

Betaxolol (BET)

Bisoprolol (BIS)

Metoprolol (MET)

Nadolol (NAD)

Oxprenolol (OXP)

Propranolol (PROP)

Sotalol (SOT)

Timolol (TIM)

Gemfibrozil (Gem) $\underline{0.405( \pm 0.106)}$

0.44

0.63

$\underline{0.298( \pm 0.075)}$

$0.012( \pm 0.007)^{\text {c.d }}$

Anti-inflammatory drugs

Beta-blockers

$0.040( \pm 0.070)$

$0.599( \pm 0.270)$

$0.147( \pm 0.129)^{\mathrm{d}}$

$0.980( \pm 0.345)$

Hypolipidemic agent
0.35

0.56

$\underline{0.498( \pm 0.074)}$

$\underline{0.403( \pm 0.096)}$

$\underline{0.240( \pm 0.067)}$

$0.086( \pm 0.023)^{\mathrm{c}}$

$0.223( \pm 0.130)^{d}$

$1.37( \pm 0.35)$

$0.484( \pm 0.012)^{\mathrm{b}}$

$0.694( \pm 0.009)$

$0.974( \pm 0.045)$

$0.433( \pm 0.058)^{\mathrm{d}}$

$\underline{0.279( \pm 0.056)}$

$0.204( \pm 0.004)^{b}$

$0.254( \pm 0.019)$

$0.348( \pm 0.052)$

$0.197( \pm 0.013)^{d}$

0.07

0.11

$\underline{0.002( \pm 0.014)}$

$\underline{0.139( \pm 0.042)}$

$0.083( \pm 0.078)$

$0.135( \pm 0.035)$

0.18

0.34

$\underline{0.144( \pm 0.044)}$

$0.083( \pm 0.055)$

$0.116( \pm 0.053)$

$0.239( \pm 0.009)^{\mathrm{b}}$

$0.298( \pm 0.016)$

$0.392( \pm 0.024)$

$0.200( \pm 0.037)^{d}$

0.13

0.17

$\underline{0.010( \pm 0.016)}$

$\underline{0.134( \pm 0.037)}$

$0.092( \pm 0.055){ }^{d}$

$0.166( \pm 0.052)$

0.13

0.20

$0.037( \pm 0.064)$

$\underline{0.19( \pm 0.05)^{\mathrm{f}}}$

$\underline{0.09( \pm 0.07)^{\mathrm{f}}}$

0.16-0.12 ${ }^{\text {a.e }} \quad \begin{aligned} & 26 \\ & 29\end{aligned}$

29

5

5

$0.097( \pm 0.066)^{\mathrm{d}}$

$\underline{0.17( \pm 0.08)^{f}}$

$\underline{\underline{0.26( \pm 0.14)^{f}}} \quad 29$

$\underline{0.23( \pm 0.12)^{\mathrm{f}}} \quad 29$

$0.12-0.06^{\text {a.e }}$

$\underline{0.10( \pm 0.06)^{f}}$

5

15 15

$\underline{0.804( \pm 0.081)}$

$0.112( \pm 0.118)^{\mathrm{d}}$

$0.192( \pm 0.034)$

$0.257( \pm 0.005)^{b}$ 
Salbutamol (Salbu)

Clenbuterol (Clenbu)

Terbutaline (Terbu)

Theophylline (Theo)

Caffeine (Caf)
$0.306( \pm 0.031)$

$0.350( \pm 0.012)$

$0.222( \pm 0.014)^{\mathrm{d}}$

0.04

0.06

$0.013( \pm 0.026)$

$\underline{0.362( \pm 0.050)}$

$\underline{0.115( \pm 0.069)}$

Other $0.002( \pm 0.012)$

$\underline{0.168( \pm 0.047)}$

$0.096( \pm 0.008){ }^{b}$

$0.151( \pm 0.018)$

$0.127( \pm 0.021)$

0.04

0.07
12

12

${ }^{\mathrm{a}}: 12 \mathrm{~cm}^{2}$ POCIS, ${ }^{\mathrm{b}}:$ temperature $\leq 10^{\circ} \mathrm{C},{ }^{\mathrm{c}}: 18 \mathrm{~cm}^{2}$ POCIS, ${ }^{\mathrm{d}}:$ Zero- or mild-turbulence media, ${ }^{\mathrm{e}}:$ mean effluent value - mean river value, ${ }^{\mathrm{f}}$ : mean of 3 campaigns across 9 sites -3 in-river upstream of a WWTP, 3 in-river downstream of a WWTP, 3 in WWTP effluent. 


\section{Supplementary material:}

Table S1: Sampling rates $\left(1 . \mathrm{d}^{-1}\right)$ for both water velocity $\left(0.21\right.$ and $\left.0.46 \mathrm{~m} \cdot \mathrm{s}^{-1}\right)$ and relative standard deviation between both.

\begin{tabular}{|c|c|c|c|}
\hline Compounds & $\begin{array}{l}\text { Rs for highest } \\
\text { velocity }\left(\mathbf{l . d}^{-1}\right)\end{array}$ & $\begin{array}{l}\text { Rs for slowest } \\
\text { velocity }\left(\mathbf{l . d}^{-1}\right)\end{array}$ & $\begin{array}{l}\text { RSD } \\
(\%)\end{array}$ \\
\hline CARBA & $0.33 \pm 0.04$ & $0.32 \pm 0.07$ & 3 \\
\hline DIAZ & $0.40 \pm 0.08$ & $0.39 \pm 0.08$ & 3 \\
\hline ALPRA & $0.50 \pm 0.07$ & $0.57 \pm 0.12$ & 10 \\
\hline BROMA & $0.40 \pm 0.10$ & $0.40 \pm 0.11$ & 1 \\
\hline TERBU & $0.12 \pm 0.07$ & $0.17 \pm 0.03$ & 27 \\
\hline SALBU & $0.01 \pm 0.03$ & $0.03 \pm 0.01$ & 49 \\
\hline CLENBU & $0.36 \pm 0.05$ & $0.35 \pm 0.07$ & 2 \\
\hline NORDIAZ & $0.39 \pm 0.08$ & $0.43 \pm 0.08$ & 7 \\
\hline FLUOX & $0.24 \pm 0.07$ & $0.19 \pm 0.10$ & 18 \\
\hline AMI & $0.41 \pm 0.12$ & $0.43 \pm 0.10$ & 4 \\
\hline IMI & $0.30 \pm 0.07$ & $0.30 \pm 0.08$ & 1 \\
\hline DOX & $0.41 \pm 0.11$ & $0.41 \pm 0.12$ & 0 \\
\hline PARA & $2.10 \mathrm{E}-03 \pm 0.01$ & $7.08 \mathrm{E}-03 \pm 1.19 \mathrm{E}-02$ & 77 \\
\hline CAF & $0.17 \pm 0.05$ & $0.17 \pm 0.05$ & 1 \\
\hline THEO & $2.26 \mathrm{E}-03 \pm 0.01$ & $4.38 \mathrm{E}-03 \pm 1.02 \mathrm{E}-02$ & 45 \\
\hline ASP & $1.03 \mathrm{E}-02 \pm 0.02$ & $1.01 \mathrm{E}-04 \pm 7.52 \mathrm{E}-02$ & 139 \\
\hline IBU & $0.28 \pm 0.06$ & $0.28 \pm 0.05$ & 0 \\
\hline GEM & $0.80 \pm 0.08$ & $0.77 \pm 0.14$ & 3 \\
\hline NAPRO & $0.14 \pm 0.04$ & $0.18 \pm 0.04$ & 14 \\
\hline DICLO & $0.13 \pm 0.04$ & $0.19 \pm 0.04$ & 25 \\
\hline KETO & $0.14 \pm 0.04$ & $0.17 \pm 0.04$ & 14 \\
\hline BPA & $0.01 \pm 0.01$ & $0.02 \pm 0.01$ & 17 \\
\hline 4-NP & $0.02 \pm 0.01$ & $0.01 \pm 0.01$ & 21 \\
\hline 4-t-OP & $0.10 \pm 0.03$ & $0.11 \pm 0.03$ & 2 \\
\hline 4-NP1EC & $0.31 \pm 0.08$ & $0.30 \pm 0.06$ & 1 \\
\hline 4-NP1EO & $9.71 \mathrm{E}-03 \pm 0.01$ & $6.65 \mathrm{E}-03 \pm 3.62 \mathrm{E}-03$ & 37 \\
\hline 4-NP2EO & $6.75 \mathrm{E}-03 \pm 0.01$ & $2.43 \mathrm{E}-03 \pm 1.17 \mathrm{E}-03$ & 66 \\
\hline
\end{tabular}

